\title{
Utilization of spent iron catalyst for ammonia synthesis
}

\author{
Walerian Arabczyk, Urszula Narkiewicz, Zofia Lendzion-Bieluń, Dariusz Moszyński, Iwona Pełech, \\ Ewa Ekiert, Marcin Podsiadły, Rafał Pelka, Roman Jędrzejewski, Izabela Moszyńska, \\ Daniel Sibera
}

\author{
Szczecin University of Technology, Institute of Chemical and Environment Engineering, ul. Pułaskiego 10, \\ 70-322 Szczecin, Poland, e-mail: zosi@ps.pl
}

\begin{abstract}
Several methods of the utilization of spent iron catalyst for ammonia synthesis have been presented. The formation of iron nitrides of different stoichiometry by direct nitriding in ammonia in the range of temperatures between $350^{\circ} \mathrm{C}$ and $450^{\circ} \mathrm{C}$ has been shown. The preparation methods of carbon nanotubes and nanofibers where iron catalyst catalyse the decomposition of hydrocarbons have been described. The formation of magnetite embedded in a carbon material by direct oxidation of carburized iron catalyst has been also presented.
\end{abstract}

Keywords: iron catalyst, iron nitrides, carbon nanotubes, nanofibers.

Presented at VII Conference Wasteless Technologies and Waste Management in Chemical Industry and Agriculture, Międzyzdroje, 12 - 15 June, 2007.

\section{INTRODUCTION}

A commercial reactor for ammonia synthesis contains from 50 to 100 tons of catalyst. Mainly it is iron with small amounts of promoters $\left(\mathrm{Al}_{2} \mathrm{O}_{3}, \mathrm{CaO}, \mathrm{K}_{2} \mathrm{O}\right)$. After several years of operation the catalyst loses its catalytic properties and is replaced by a new one. The loss of catalytic properties is connected with the poisoning processes, as well as with strength drop and grain disintegration which can result in the increase of pressure drops. Recovery processes allowing the re-application of the catalyst are still studied but nowadays the spent catalyst is used as a scrap in the ironworks. Because of its nanocrystalline structure with a well-developed specific surface area (near $10 \mathrm{~m}^{2} / \mathrm{g}$ ) it is a very reactive material and, therefore other applications of this precious material are examined. It can be used to obtain nanocrystalline nitrides, nanocarbon materials and materials for xerographic powders.

In the case of fine-crystalline nitrides formation, on account of their final form, one can distinguish:

- obtaining iron nitrides in the form of the amagnetic fluid $^{1,2}$,

- obtaining iron nitrides in the form of fine-crystalline powders and cemented nitrides ${ }^{3-6}$,

- obtaining nitrides in the form of thin films and foils $7-9$.

Fine-crystalline iron nitrides are resistant to oxidation and atmospheric agents ${ }^{\mathbf{1 0}}$. They prove high strength, hardness and durability, as well as very good magnetic properties such as high magnetic inductivity, high magnetic flexibility, high magnetic permeability, low coercion and magnetic softness. Fine-crystalline nitrides in the form of films reduce the eddy current and prove high specific electrical resistivity.

A spent iron catalyst can also be used for the production of nanomaterials containing iron and carbon. A number of preparation methods of nanocarbon materials were developed during the last decade. One of the simplest and most inexpensive methods is chemical vapor deposition (CVD). The best catalysts for the preparation of such nanocarbon materials are based on iron, nickel and cobalt ${ }^{11-18}$. Preparation conditions in the method are not difficult and the process is easy to control. The method can also be up - scaled to industrial relevance. During a chemical vapor deposition different carbon structures can be obtained, some of them having very interesting properties, as carbon nanotubes or nanofibers. The spent iron catalyst can also be applied as a source of iron for the production of nanocrystalline iron carbides. These materials can be obtained by decomposition of hydrocarbons (methane, ethane, ethylene) on iron catalyst. Such materials can be applied as fillers for polymer composites, magnetic materials for data storage, magnetic toners in xerography, magnetic inks and ferrofluids.

At The Institute of Chemical and Environment Engineering several applications of spent iron catalyst for ammonia synthesis were elaborated, e.g. the formation of nanocrystalline iron nitrides and carbides, of carbon nanotubes and nanocapsules, of iron nanopowder, of iron encapsulated in carbon and the preparation of xerographic toners. In this work the preparation and characterisation methods of those materials were presented.

\section{EXPERIMENTAL}

An analytical system (Fig. 1) equipped with a tubular reactor was used to perform investigations on the reduction, nitriding, carburisation and oxidation of a spent iron catalyst. In a platinum basket hanging on the balance arm ca. $1 \mathrm{~g}$ of the analyzed substance was placed in the form of a single layer of grains. Thermogravimetric measurements combined with an analysis of gas phase composition were conducted. The resolution of mass changes measurement was $0.1 \mathrm{mg}$. The applied gases, i.e. hydrogen, HCs, ammonia and nitrogen were let into the reactor from a gas cylinder through the reduction valves. The flow rate of the gases was determined by means of mass flow controllers. In order to analyze gas composition the gas samples were collected over and under the platinum basket. The mass and temperature of the analyzed solid sample as well as the data concerning gas concentrations in the gas mixture were recorded digitally. 


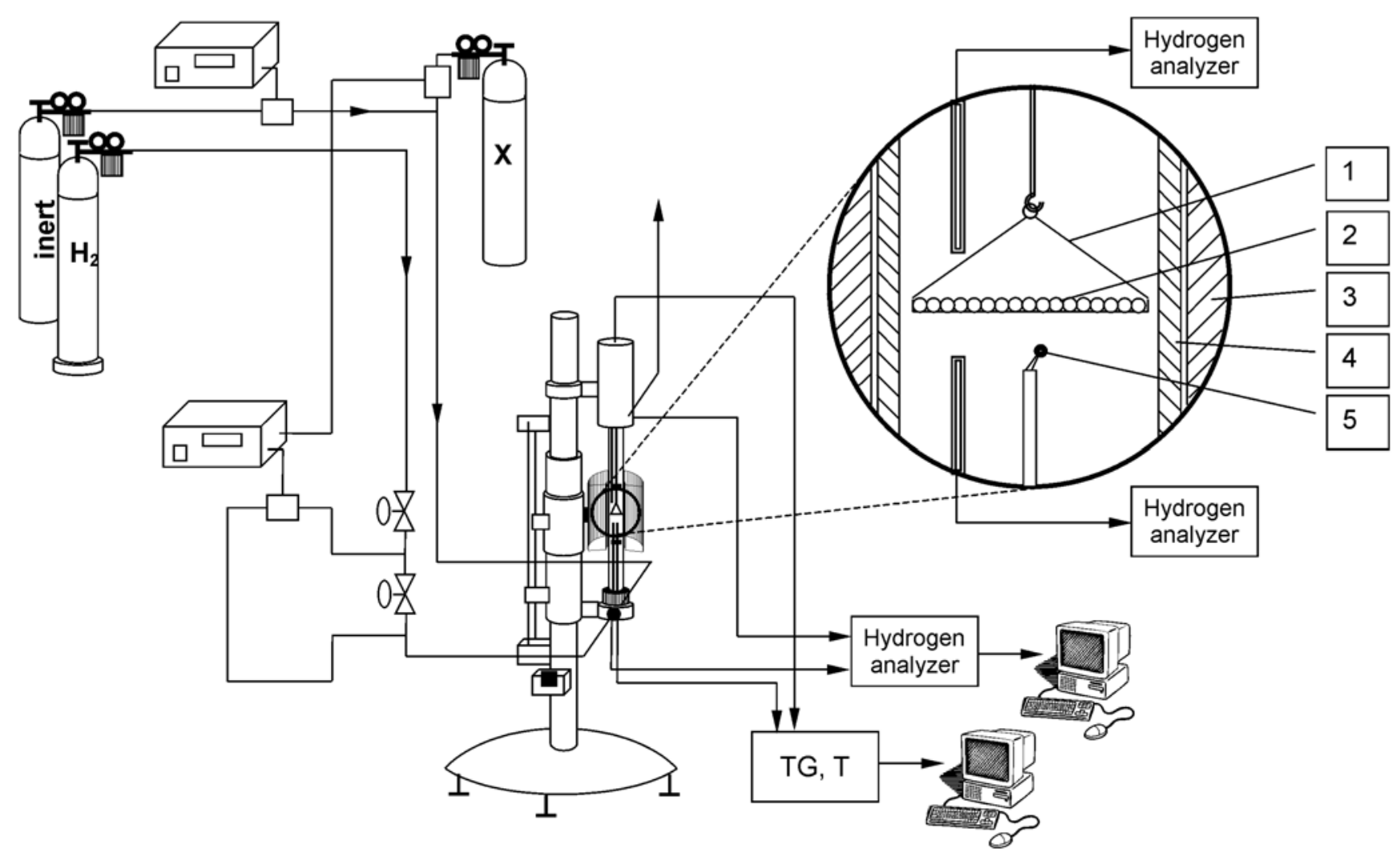

Figure 1. The experimental setup. 1 - sample holder, 2 - single layer of grains, 3 - reactor furnace, 4 - reactor wall, 5 thermocouple, $\mathrm{X}=\mathrm{NH}_{3}, \mathrm{HC}, \mathrm{O}_{2}$

Before the process each sample was reduced polythermally under the hydrogen flow $(40 \mathrm{l} / \mathrm{h})$ at the temperature raising from $20^{\circ} \mathrm{C}$ to $500^{\circ} \mathrm{C}$. The reduction process was carried out in order to remove a thin passivation layer.

Nitriding processes were conducted under ammonia atmosphere (1 bar) under isothermal conditions, at various temperatures from the range $350-450{ }^{\circ} \mathrm{C}$, at ammonia load $500 \mathrm{~cm}^{3} \mathrm{~min}^{-1} \mathrm{~g}^{-1}$ mat until the analyzed sample mass was stable, which could be observed on the TG curves as a horizontal line. The reacting gas mixture composition was also determined.

The carburisation processes were performed under the methane, ethane or ethylene flow $(40 \mathrm{l} / \mathrm{h})$, pure or mixed

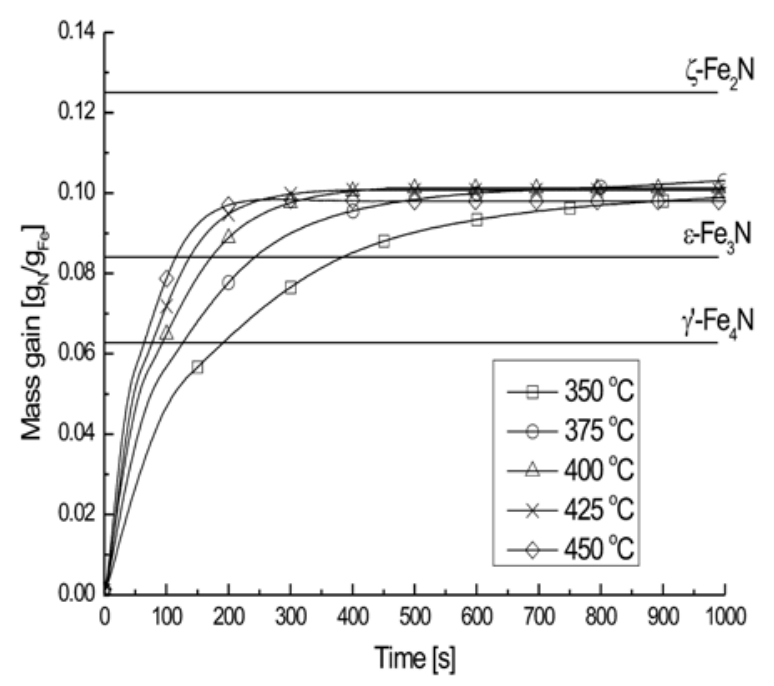

Figure 2. The TG curves for the nitriding process of nanocrystalline iron with hydrogen or argon, under atmospheric pressure, isothermally, in the temperature range between 340 and $550^{\circ} \mathrm{C}$. After the carburisation process the samples were cooled to the room temperature under the nitrogen flow.

To obtain xerographic black powders the samples of the iron catalyst after the reduction were carburized with the use of pure methane at the temparature of $660^{\circ} \mathrm{C}$ as long as the carburization degree reached the value between 0,072 and 2. After the completion of the carburization process, methane was replaced with nitrogen and the sample was cooled down to the temperature from the range of $300-450^{\circ} \mathrm{C}$. Next the oxidation process was carried out at planned temperature with the nitrogen stream saturated with water vapour.

The samples obtained in the processes, described above, were characterized using X-ray diffraction on the Philips $\mathrm{X}$ 'Pert diffractometr with the use of $\mathrm{CuK} \alpha$ radiation $(\lambda=0.15418 \mathrm{~nm})$ as well as by the high resolution transmission electron microscopy Jeol JEM 3010.

\section{RESULTS AND DISCUTION}

\section{Nanocrystalline iron nitrides}

The results of the selected experiments are presented in Fig. 2 and 3 in the form of the TG curves and the gas phase composition changes, respectively. The conversion of iron nitriding reached the maximum and remained unchanged at each temperature over the twofold longer time than it is shown in Fig. 2, despite a prolonged exposure to the nitriding atmosphere. There can be observed some inflection points on the TG curves, which implies, that the analyzed iron nitriding has many stages. The curve sections, which are observed between the inflection points, can be considered as approximately linear. The formation 


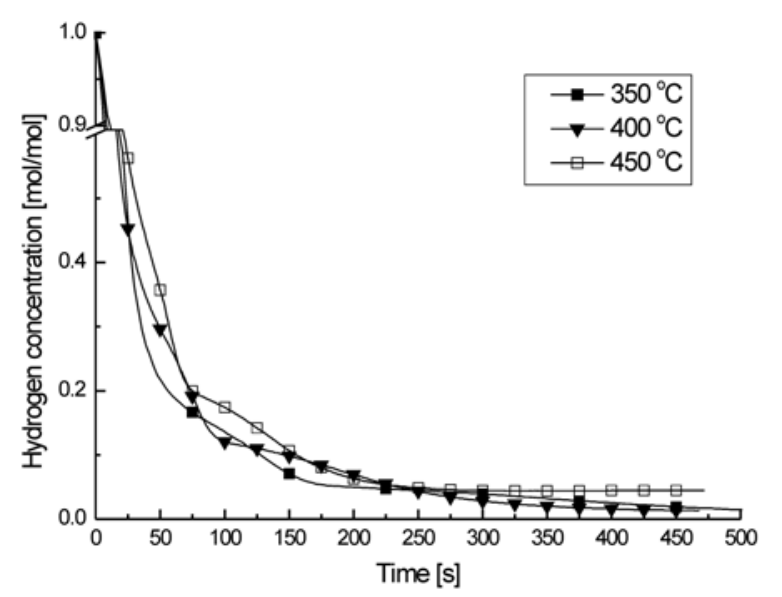

Figure 3. The gas phase composition changes - the nitriding process

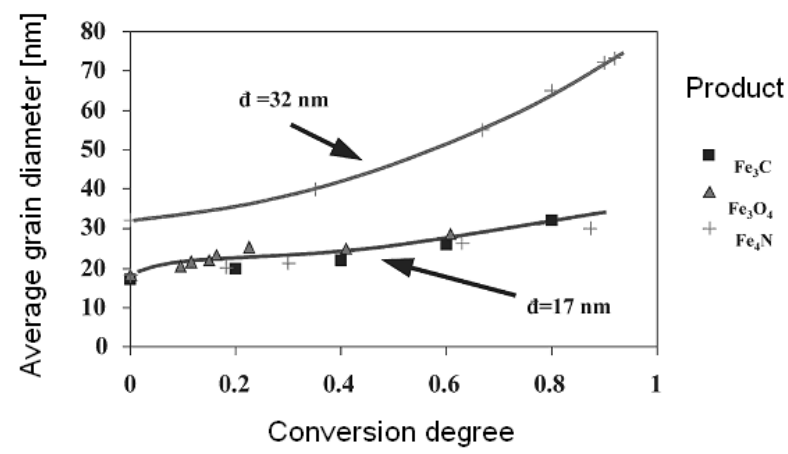

Figure 4. An average grain size diameter of iron crystallites vs. the conversion degree ${ }^{\mathbf{1 9}}$

of nitrides $\gamma-\mathrm{Fe}_{4} \mathrm{~N}$ and $\varepsilon-\mathrm{Fe}_{3-2} \mathrm{~N}$ was observed. At temperatures greater than $400^{\circ} \mathrm{C}$, notable catalytic ammonia decomposition takes place on iron ${ }^{34,35}$. Therefore, a decrease of ammonia concentration observed in a stationary state (Fig. 3) results only from the catalytic ammonia decomposition.

The mean size of iron nanocrystallites as well as the phase composition of the obtained samples by means of XRD have been determined. The increase of the measurements of the average crystallite size with the increase of conversion has been noted (Fig. 4).This dependence cannot be explained on the basis of the shrinking core model or the crackling core model, which were developed to describe the processes in the solid- gas systems for coarse-grained materials.

It was shown ${ }^{20,21}$ that the rate of the entire nitriding of iron is limited by ammonia adsorption on the iron surface only during the initial stage of nitrogen absorption in iron bulk. Ammonia located on the iron surface undergoes the decomposition resulting in atomic nitrogen and hydrogen. Atomic nitrogen dissolves in iron bulk, while hydrogen molecules desorbed. When nitriding process rate is limited by the rate of dissotiative adsorption of ammonia on iron surface (adsorption range model), the nitrogen concentration gradient in iron crystallites does not occur. The phase transition of iron crystallites saturated with nitrogen to iron nitrides is observed when the critical concentration of nitrogen in iron is exceeded. The surface reaction rate does not depend on the crystallites' diameter, and nitrogen concentration in the bulk of iron crystallites at the given moment of reaction depends on the ratio of the crystallite surface area to the crystallite volume. Thus, the critical concentration is reached first in small crystallites and then in the big ones, which means that along with the nitriding process proceeding the iron crystallites undergo the phase transition to iron nitride $\mathrm{Fe}_{4} \mathrm{~N}$ according to their sizes ${ }^{22}$.

\section{NANOCARBON MATERIALS}

The carburisation of nanocrystalline iron under pure ethylene at the temperature of $500^{\circ} \mathrm{C}$ and $550^{\circ} \mathrm{C}$ was performed. The spent iron catalyst without potassium was used (potassium compounds were eliminated by washing with hot water). The processes were carried out to an increase of the carbon mass to about 0.7 and $1.3 \mathrm{gC} / \mathrm{gFe}$, respectively. The relative increase of carbon mass as a function of carburisation time is shown in Fig. 5. In both cases the reaction rate is maximal at the beginning of the process. The relative increase of carbon mass is almost twice greater for the sample carburised at $550^{\circ} \mathrm{C}$ than that carburized at $500^{\circ} \mathrm{C}$.

The sample of iron catalyst before and after the carburisation at $500^{\circ} \mathrm{C}$ was characterized using X-ray diffraction (Fig. 6). The diffraction pattern No 1 corresponds to the sample of the nanocrystalline iron before the carburisation process. In this pattern only the peaks character-

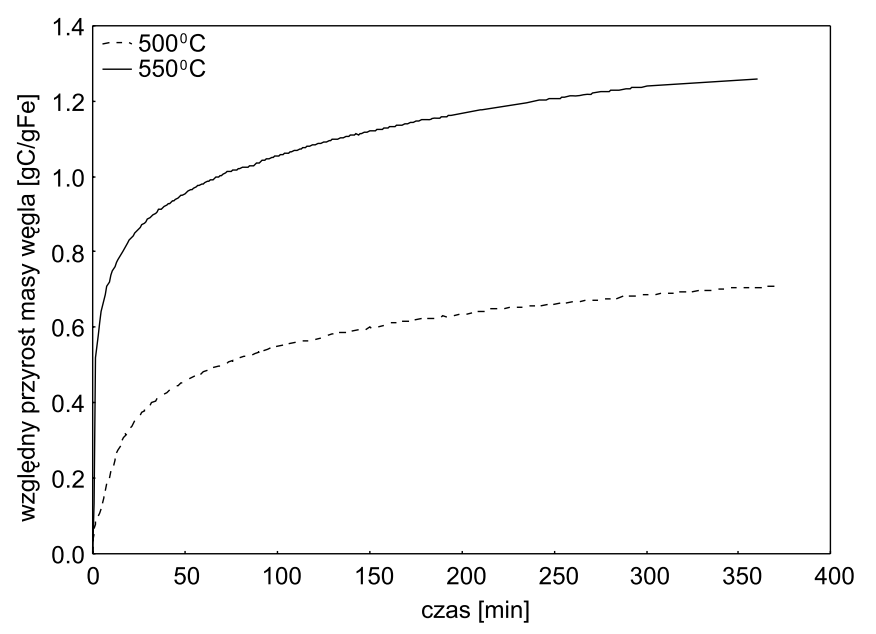

Figure 5. The TG curves of the carburisation process of nanocrystalline iron with ethylene

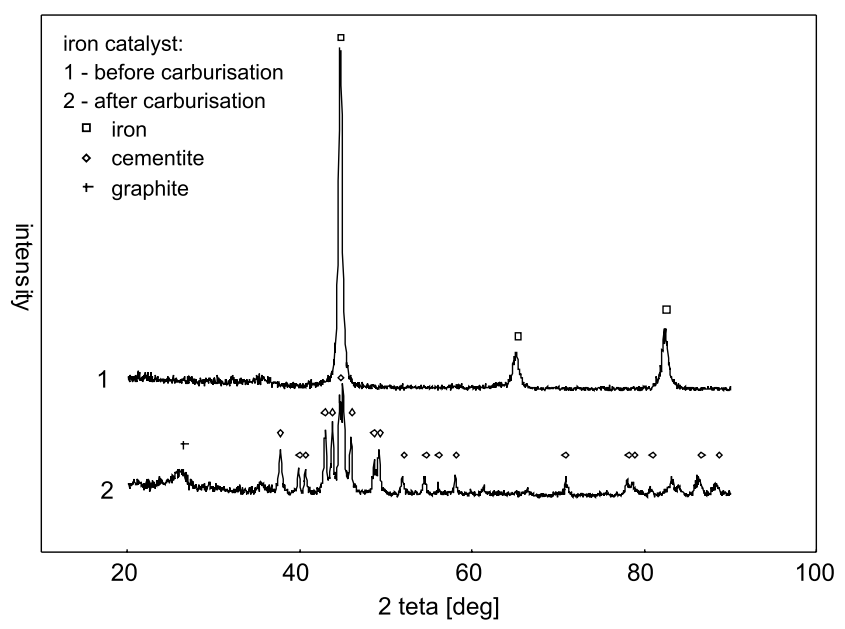

Figure 6. The diffraction patterns: No 1 - nanocrystalline iron sample, No 2 - the sample after carburisation at $500^{\circ} \mathrm{C}$ 

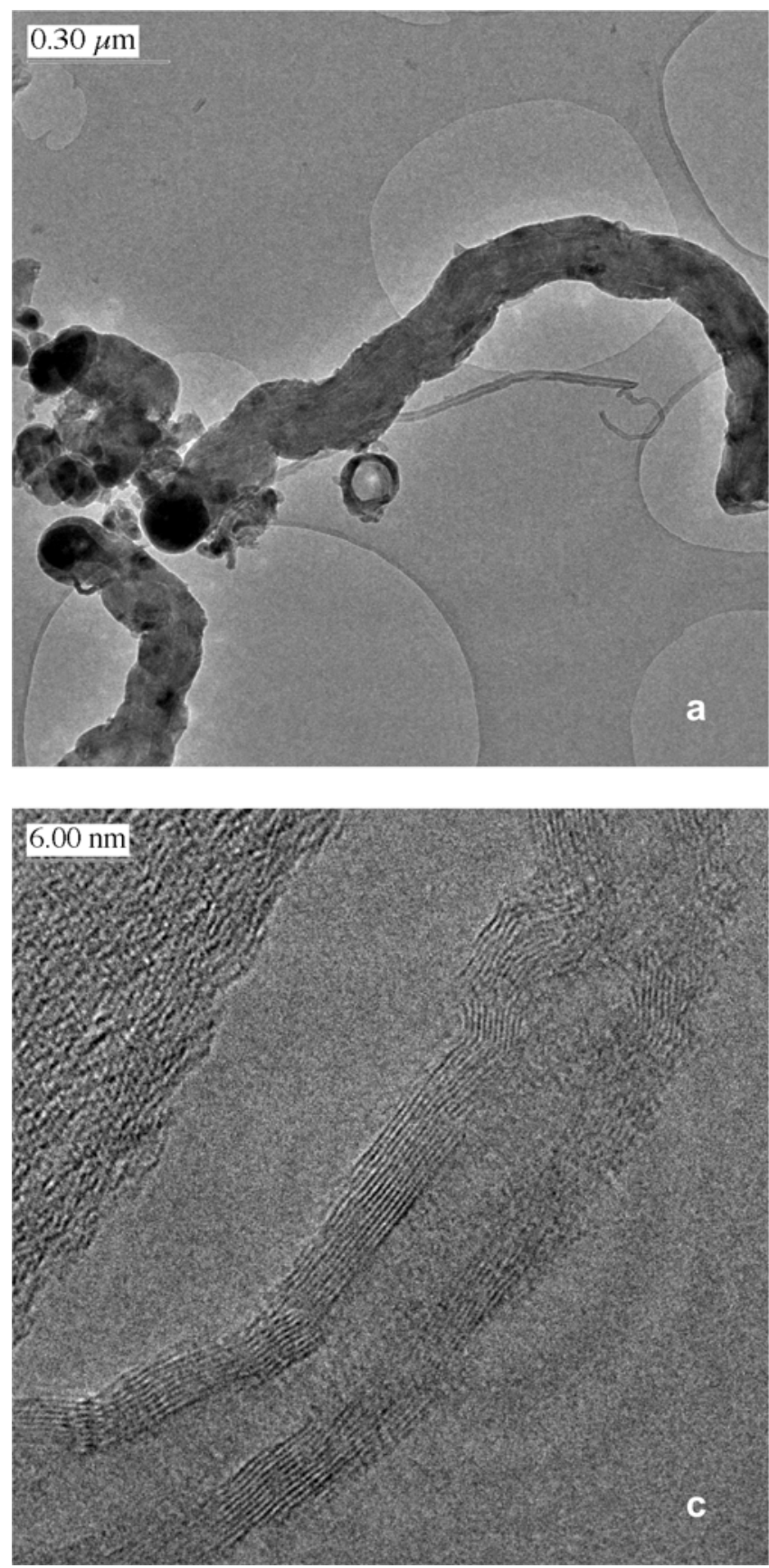

Figure 7. The HRTEM image of the sample after carburisation at $550^{\circ} \mathrm{C}$

istic of $\alpha$-Fe were observed. The diffraction pattern No 2 corresponds to the sample of the nanocrystalline iron after carburisation process. The peaks corresponding to the cementite $\left(\mathrm{Fe}_{3} \mathrm{C}\right)$ were detected. Under the experimental conditions other iron carbides were not observed. In this diffraction pattern the peaks corresponding to the unconverted $\alpha$-Fe were not present which indicates that the whole iron was converted to cementite. If the sample was carburised above the stoichiometric composition of $\mathrm{Fe}_{3} \mathrm{C}(0.072 \mathrm{gC} / \mathrm{gFe})$, that unconverted $\alpha$-Fe was not observed and some part of carbon remained in the form of carbon deposit. In this case the peak of graphite at $2 \Theta=$ $26^{\circ}$ was observed.

The morphology of carbon deposits was also investigated. The sample of nanocrystalline iron was carburised under ethylene at $550^{\circ} \mathrm{C}$. As a result the carbon content in the sample was $1.3 \mathrm{gC} / \mathrm{gFe}$. Fig. 7 presents a HRTEM image of this sample. The sample contains mainly carbon nanofibers (Fig. 7a, 7b). The fibers are about $100 \mathrm{~nm}$ in diameter. Some carbon nanotubes are also present (Fig.
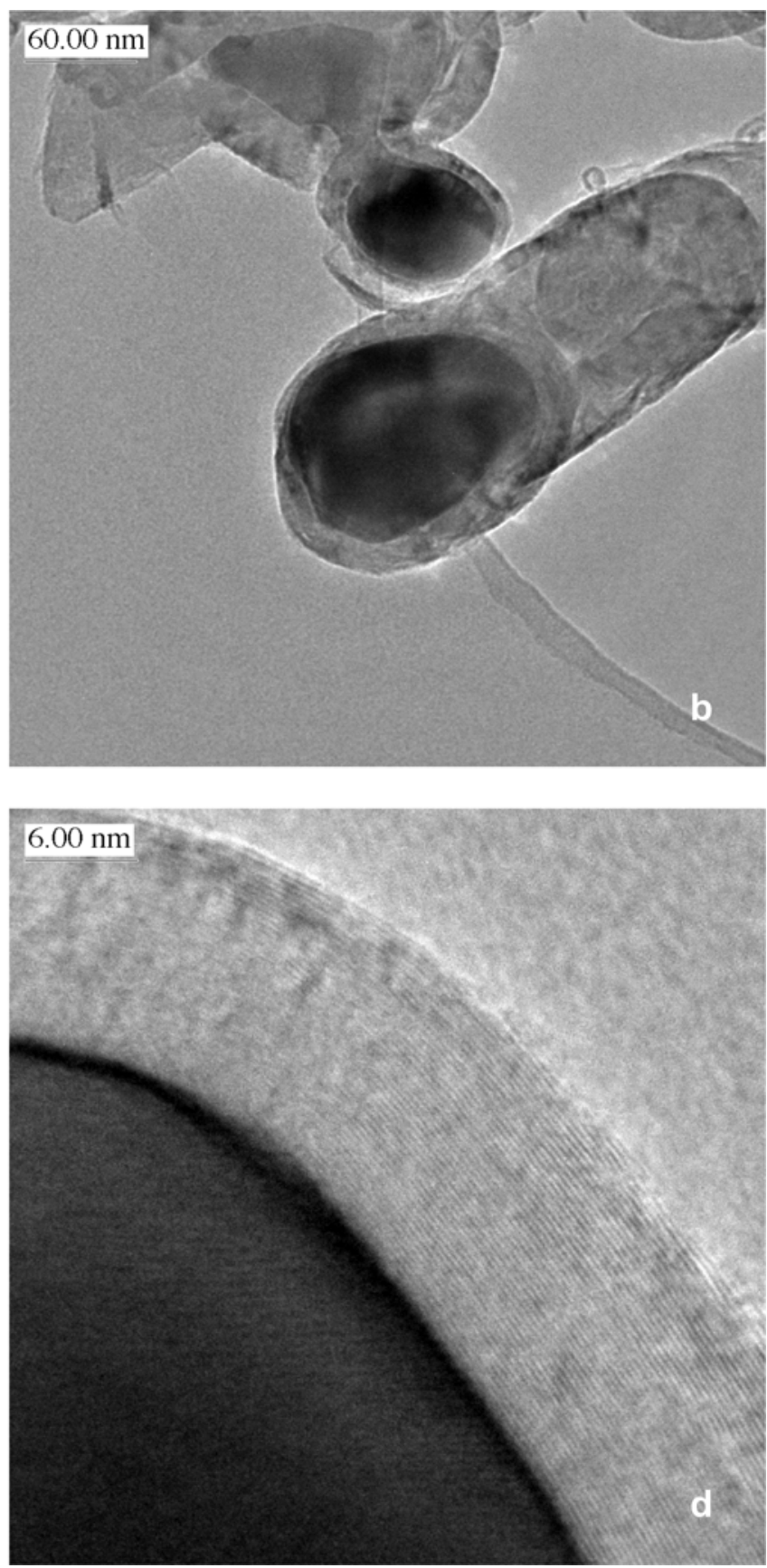

$7 \mathrm{~b}, 7 \mathrm{c})$. The nanotubes were multi-wall carbon nanotubes (Fig. 7c). The diameter of the nanotubes was in the range of $10-30 \mathrm{~nm}$. At the end of the fibrous carbon structure some crystallites of iron carbide were visible (Fig. 7a, 7b). The size of cementite crystallites was in the range $50-$ $150 \mathrm{~nm}$. The nanoparticles of cementite were surrounded by some layers of graphite (Fig. 7d). The layer distances between graphite sheets were about $0.34 \mathrm{~nm}$.

To obtain iron carbide without carbon deposit, the lower rate of the carburisation has been examined.

In this case this sample of iron catalyst was carburised under ethylene - hydrogen flow $(1: 19)$ at $370^{\circ} \mathrm{C}$. The sample was carburised until the carbon mass increased to about $0.04 \mathrm{gC} / \mathrm{gFe}$. An example of a TG curve during the preparation of the samples containing iron and cementite is presented as the lower line 2 in Fig.8, comparing to the carburisation under undiluted ethylene (line 1).

Cementite can be also produced through methane decomposition on the iron catalyst at temperatures lower than $500^{\circ} \mathrm{C}$. The example of the $\mathrm{TG}$ curve registered for 


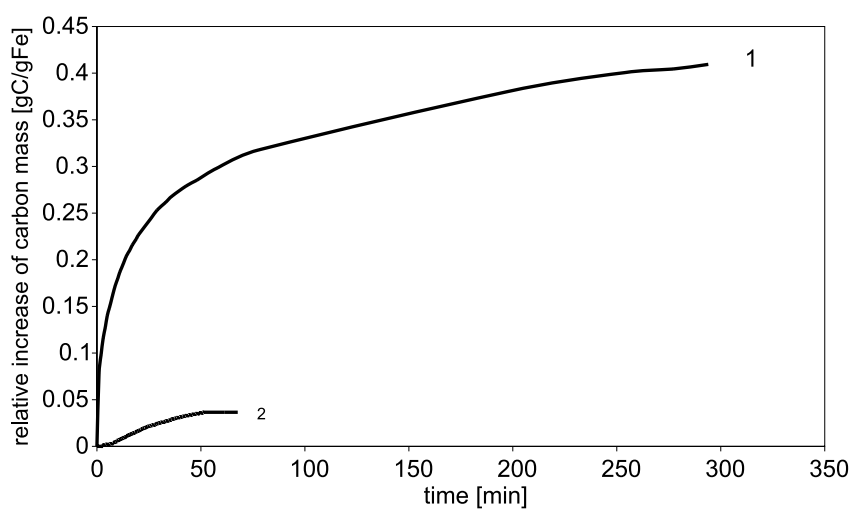

Figure 8. The effect of ethylene dilution on the carburisation rate: 1 - pure ethylene at $550^{\circ} \mathrm{C}, 2$ - ethylene - hydrogen mixture flow $(1: 19)$ at $370^{\circ} \mathrm{C}$

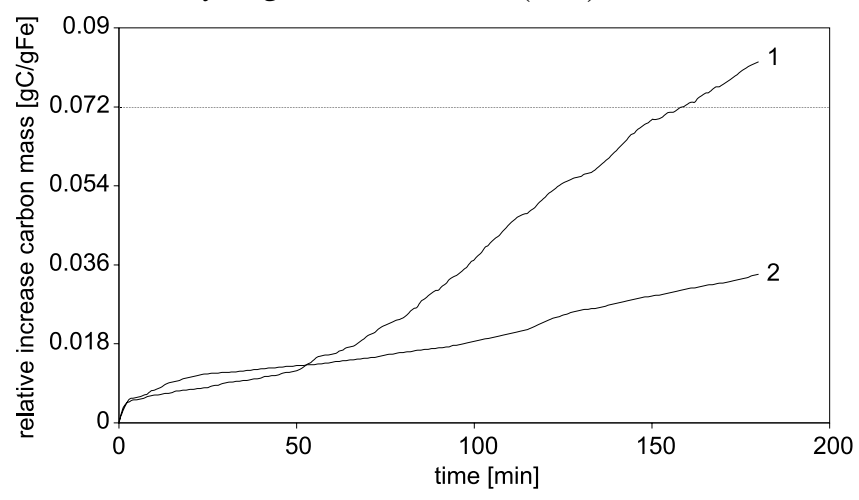

Figure 9. Decomposition of methane on the iron catalyst at $500^{\circ} \mathrm{C}$ : 1 - spent iron catalyst without potassium, 2 - spent iron catalyst

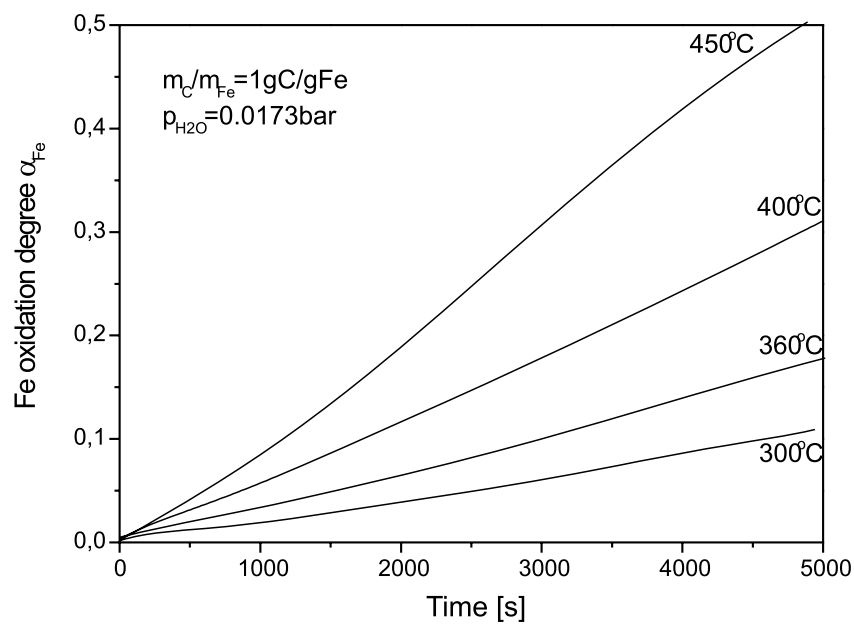

Figure 10.The dependence of the iron oxidation degree on the temperature of the oxidation process

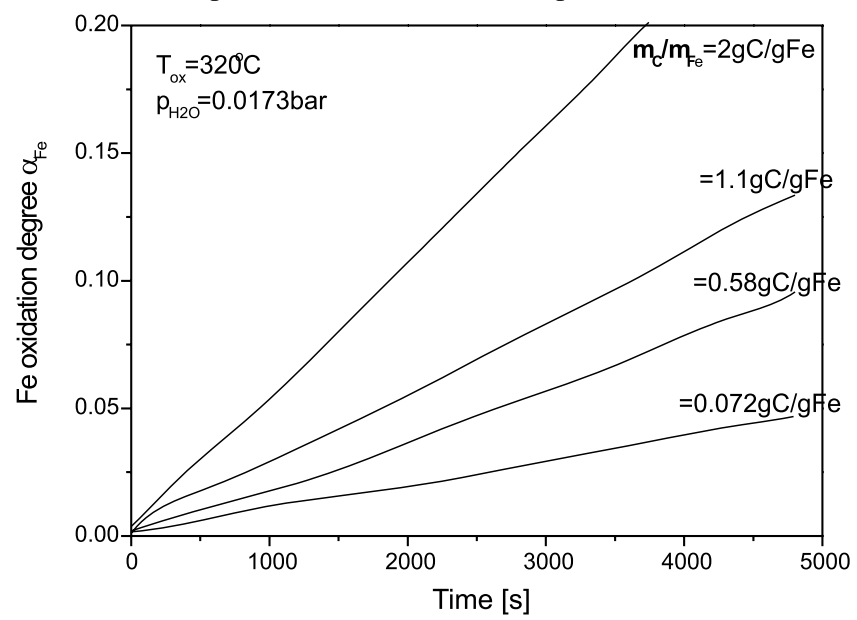

Figure 11. The dependence of the iron oxidation degree on a different carburization degree

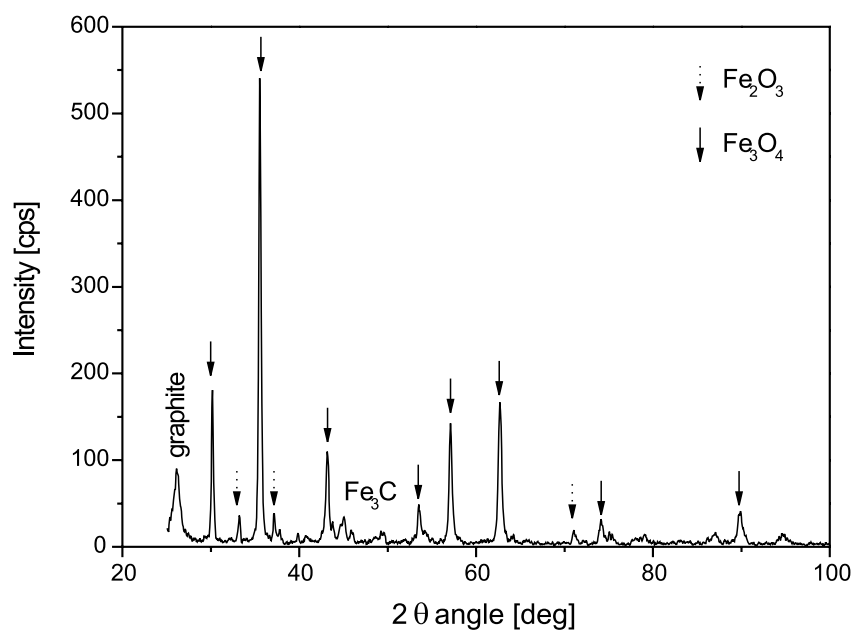

Figure 12.The XRD pattern of the sample after the carburization and oxidation process

the decomposition of methane on the iron catalyst at the temperature of $500^{\circ} \mathrm{C}$ is shown in Fig. 9 (line 2). In this process only cementite is formed, no carbon deposit is observed. However, the elimination of potassium from iron catalyst causes the increase of carburisation rate and in this case the parallel formation of cementite and carbon occurs (TG line 1 in the figure 9).

The appropriate choice of temperature and carburising gas - the different iron-carbon nanomaterials can be obtained (cementite, carbon nanotubes or nanocapsules) by.

At The Institute of Inorganic and Environmental Engineering the studies are carried out on using the nanocrystalline iron catalyst as a substrate to produce the magnetite in carbon matrix. In the first step of this process the nanocrystalline iron is carburised with hydrocarbon to obtains given carburization degree. On this way the samples series of iron carbide in carbon matrix (as shown in Fig. 6) was obtained, with carbon concentration in the range $\mathrm{m}_{\mathrm{C}} / \mathrm{m}_{\mathrm{Fe}}=0,072-2$. Next, the mixture of carbon and iron carbide was oxidized by traces of water vapour in the nitrogen stream under the required conditions. The dependence of the iron oxidation degree on the temperature of the oxidation process is shown in Fig. 10. The carburization degree and water vapour concentration were constant. The oxidation rate increases with the temperature. In the initial stage of the oxidation the TG curves are linear. It means that the reaction rate is constant and in this region it's dependent on the iron oxidation degree a.

The influence of the carburization degree on the oxidation rate was examined. The TG curves obtained for the oxidation process of the samples with a different carburization degree are shown in Fig.11. The oxidation rate of the sample with the carburization degree $\mathrm{m}_{\mathrm{C}} / \mathrm{m}_{\mathrm{Fe}}=2$ is much higher than pure iron without carbon deposit. The oxidation rate increases with the carburization degree though the active sites on the iron surface are occupied with carbon.

The exemplary XRD pattern of the sample after the oxidation process is shown in Fig.12. The identified crystallographic phases are marked. The carburization degree $\mathrm{m}_{\mathrm{C}} / \mathrm{m}_{\mathrm{Fe}}=1$ and iron oxidation degree $\alpha=0,77$. Graphite, magnetite, a small amount of hematite and unreacted iron carbide have been identified in the sample. The obtained mixture of iron oxides in carbon matrix can be used as a black filler in the polymer base in toners. 


\section{CONCLUSIONS}

The utilization of the spent iron catalyst is an important environmental and technological problem. Herein there were presented several chemical methods to recycle this material and use it for the production of useful new products. The preparation of iron nitrides and carbide with interesting magnetic properties was described. Iron can be used to obtain nanometric carbon materials. It was also shown that the iron compounds, such as magnetite, can be embedded in the nanocarbon structures.

\section{LITERATURE CITED}

(1) Isao N., Kiyoshi O.: Patent Abstracts of Japan, 1993, Nr. 05070784 A.

(2) Hirokazu Y.: Patent Abstracts of Japan, 1994, Nr. 06122503 A.

(3) Kieffer R., Hotop W.: „Metalurgia proszków i materiały spiekane”, Katowice 1951.

(4) Hirokazu Y.: Patent Abstracts of Japan, 1994, Nr. 06157012 A.

(5) Koichiro M., Takuo T.: 1992, Patent Abstracts of Japan, Nr. 04293701 A.

(6) Koichiro M., Takuo T.: 1993, Patent Abstracts of Japan, Nr. 05043901 A.

(7) Isao N., Takashi S.: Patent Abstracts of Japan, 1993, Nr. 05286704 A, Nr. 05286705 A.

(8) Shoichi T.: Patent Abstracts of Japan, 1994, Nr. 06069032 A.

(9) Legkaja T. N., Moskalenko Ju. N., Permjakov V. G.: Zavodskaja laboratorija, 1972, 11, 1360.

(10) Mikio K., Wasaburo O.: Patent Abstracts of Japan, 1994, Nr. 06128729 A.

(11) Gulino G., Vieira R, Amadou J., Nguyen P., Ledoux M. J., Galvagno S., Centi G., Pham-Huu C.: Applied Catalysis A: General, 2005, 279, 89.

(12) Rodriguez N. M., Kim M. S., Fortin F., Mochida I., Baker R. T. K.: Applied Catalysis A: General, 1997, 148, 265.

(13) Qian W., Liu T., Wei F., Wang Z., Li Y.: Applied Catalysis A: General, 2004, 258, 121.

(14) Wang H. Y., Rucknstein E.: Carbon, 2002, 40, 1911.

(15) Wang P., Tanabe E., Ito K., Jia J., Morioka H., Shishido

T., Takehira K.: Applied Catalysis A: General, 2002, 231, 35.

(16) Lim S., Shimizu A., Yoon S., Korai Y., Mochida I.: Carbon, 2004, 42, 1273.

(17) Qian W., Liu T., Wang Z., Yu H., Li Z., Wei F., Luo G.: Carbon, 2003, 41, 2487.

(18) Meisen U., Kathrein H.: J. Imaging Sci. Technol., 2000, 44, 508.

(19) Arabczyk W.: Zamłynny, J. Catal. Lett., 1999, 167, 60.

(20) Wróbel R., Arabczyk W.: Solid-Gas Reaction with Adsorption as the Rate Limiting Step, J. Phys. Chem. A, 2006, 110 (29), 9219.

(21) Wróbel R.: Praca doktorska, Instytut Technologii Chemicznej Nieorganicznej i Inżynierii Środowiska, Politechnika Szczecińska, 2003.

(22) Arabczyk W., Wróbel R.: Study of the kinetics of nitriding of the nanocrystalline iron using the TG and XRD methods, Solid State Phenomena, 2003, 94, 185. 